УДК 791.634: 628.9

Журба Яніна Олексї̈ва

аспірантка

Київський національний університет

культури і мистецть

Kиїе, Україна

iana@zzjazz.com

\title{
ФОРМА 12-ТАКТОВОГО БЛЮЗУ ЯК ФЕНОМЕН МУЗИЧНОЇ НЕАКАДЕМІЧНОЇ КУЛЬТУРИ ХХ СТОЛІТТЯ
}

Мета роботи. дослідити вплив блюзу на неакадемічну музичну культуру XX століття, спираючись на аналіз музичної форми 12-тактового блюзу. Методологічною основою дослідження $\epsilon$ системний підхід, який $є$ характерним для культурології, та за допомогою якого можна здійснити різнобічний аналіз неакадемічної музики XX ст. Наукова новизна. Розвиток сучасного неакадемічного музичного мистецтва $є$ можливим лише через вивчення його витоків та розвитку. Тому дослідження саме блюзу, як витоку багатьох стилів неакадемічної музичної культури XX ст. с вельми актуальним. Висновки. Блю3, зокрема музична форма 12-ти тактового блюзу, дійсно $\epsilon$ неординарним та основоположним явищем в неакадемічній музичній культурі XX ст. Логіку музичної форми 12-тактового блюзу, ступінь узагальнення досвіду передуючих ій музичних жанрів, іiі вплив на подальші музичні напрями та стилі можна порівняти навіть не тільки 3 8-ми тактовим періодом у класичній музиці, а навіть 3 формою «сонатного алегро».

Ключові слова: блю3, 12-тактовий блюзовий квадрат, неакадемічна музична культура XX ст.

Журба Янина Алексеевна, аспирантка, Киевский национальньй университет культуры и искуссть, Киев, Украина

Форма 12-тактового б.лоза как феномен музыкальной неакадемической культуры XX века

Цель работы: исследовать влияние блюза на неакадемическую музыкальную культуру XX века, опираясь на анализ музыкальной формы 12тактового блюза. Методологической основой исследования является системный подход, который характерен для культурологии, и с помощью которого можно осуществить разносторонний анализ неакадемической музыки XX ст. Научная новизна. Развитие современного неакадемического музыкального искусства 
возможно лишь через изучение его истоков и путей его развития. Поэтому исследования именно блюза, как источника многих стилей неакадемической музыкальной культуры ХХ века является весьма актуальным. Выводы. Блюз, в частности музыкальная форма 12-ти тактового блюза, является действительно неординарным и основополагающим явлением в неакадемической музыкальной культуре XX века. Логику музыкальной формы 12-тактового блюза, степень обобщения опыта предшествующих ей музыкальных жанров, ее влияние на последующие музыкальные направления и стили можно сравнить не только с восьми тактовьм периодом в классической музыке, а также с формой «сонатного аллегро».

Ключевые слова: блю3, 12-тактовый блюзовый квадрат, неакадемическая музыкальная культура ХХ века.

Zhurba Yanina, postgraduate, Kyiv National University of Culture and Arts, Kyiv, Ukraine

The form of 12-bar blues as a phenomenon of music non-academic culture of the 20 th century

The purpose of the article is to investigate the influence of blues on nonacademic music culture of the 20 th century, based on the analysis of the musical form of 12-bar blues. The methodology of the research consisted in the systemic approach, which is characteristic of culturology, and with the help of which it is possible to conduct a comprehensive analysis of non-academic music of the 20 th century. The scientific novelty. The development of modern non-academic music art is possible only through studying its origins and evolution. Therefore, studying blues as the source of many styles of non-academic music culture of the 20th century is very topical. Conclusions. Blues, in particular the musical form of 12-bar blues, truly is an extraordinary and fundamental phenomenon in nonacademic music culture of the 20th century. The logic of the musical form of 12-bar blues, the degree of generalization of the experience of the preceding music genres, and its influence on the subsequent music genres and styles can be compared not only with the 8-bar age in classical music but also with the form of «sonata allegro».

Key words: blues, 12-bar blues, non-academic music culture of the 20th century.

Вступ. Вивчення неакадемічної, а зокрема джазової, музичної культури на сьогодніпній день є актуальним питанням. Про блюз, як складову частину джазової музичної культури писали Конен В. Д. («Рождение джаза», 1990, «Пути американской музыки. Очерки по истории музыкальной культуры 
США», 1965), Ломакс А. («The Land Where the Blues Began», 1993), Джиойя Т. («The History of Jazz», 1998, «How to Listen to Jazz», 2016), Яноу C. («Jazz A Regional Exploration», 2005), П. Сільвестер («The Story Of Boogie Woogie. A Left Hand Like God», 2009), Берендт Й. та Хьюсман Г. («The Jazz Book. From Ragtime to the 21st Century», 2009), Лопес П. («The Rise of a Jazz Art World», 2009), Хо A. («The Jazz Process», 2010), Верменич Ю. («Джаз: История. Стили. Мастера», 2011).

Досліджения музичного стилю блюз в історичному ракурсі проведено в роботі Коллієра Д. («Становление джаза. Популярный исторический очерк», 1984) [2]. Про характерні особливості блюзової мелодики та гармонії писав Чугунов Ю. («Эволюция гармонического языка джаза, 1997) [8]. Загальні дослідження, що до блюзових творів та творчості блюзових виконавців викладені в роботі Цалера I. («Популярная музыка XX века: джаз, блюз, поп, рок, кантри, фолк, электроника, соул», 2012) [7].

В українському музикознавстві ця тема є малодосліджена.

Мета даної статті - дослідити форму 12-ти тактового блюзового квадрату та їі вплив на музичну неакадемічну культуру XX ст.

Блюз (англ. blues - скор. від blue devils - меланхолія, журба) - це музичний напрям, який виник в Америці наприкінці XIX століття та набув неабиякого розвитку в XX ст. Саме цей музичний напрямок ліг в основу величезної кількості музичних стилів і напрямків неакадемічної музики, таких як джаз, кантрі, фанк, рок-енд-рол, джаз-рок і т.ін. Визначним є той факт, в процесі розвитку блюз перетворився на фундаментальний та самостійний музичний стиль неакадемічної музики XX ст., який існує i донині.

Існують різні музичні структури блюзів: 8-ми тактові, 12-ти тактові, 16-ти тактові та ін. Також відомі і особливі форми блюзу: мінорний блюз («Equinox», «Mr. PC»), блюзовий вальс («All Blues», «Footprints», «Bluesette», «Nutville»), блюз з бріджем («Locomotion») та комбіновані форми блюзу (мінорний блюз "Equinox», blues waltz "Gary's Notebook», descending blues "Blues for Alice», «Laid Baird», «Jack Sprat») [15, с. 223-246]. Але найпоширенішою та найзначнішою вважасться саме 12-ті тактова структура, яка навіть стала свосрідним синонімом жанру блюз. Ї̈̈ значимість у формуванні неакадемічної музики XX ст. можна зіставити зі значенням 8-ми тактового періоду для процесу становлення класичної західно-свропейської музики. Але 12-тактовий блюзовий період $\epsilon$ чимось більшим, ніж суто структурним елементом музичної форми неакадемічної музики XX ст. За ознаками він $є$ самостійним музичним жанром, який неабияким чином вплинув на всі без виключень музичні стилі неакадемічної музики минулого століття. Серед них: jazz, rock, funk, rock'n'roll, rhythm-and- 
blues, soul, hip-hop, disco, rap та ін. Важко знайти наукову роботу в області музикознавства, що стосується неакадемічної музики XX ст., в якої не була б рсвітлена тема блюзової музики. Серед них: М. Стернс «The Story of Jazz», В. Конен «Третий пласт: новые массовые жанры в музыке XX века», Ю. Чугунов «Эволюция гармонического языка джаза» та ін. Відомий американський джазовий гітарист К. Крістіансен починає свою роботу «Bebop Blues» саме з надання інформації про типовий «архаїчний» блюзовий квадрат, розглядаючи всі новаторські зміни бібопової гармонії, як похідні від нього [10, с. 5].

Так що ж саме стало причиною такого пाирокого та стрімкого світового розповсюдження такої зовсім невеликої, на перший погляд, музичної форми? Що саме привернуло увагу людства до блюзового квадрату на такий довгий час після всіх значних та геніальних творів Баха, Моцарта та Шопена?

В теорії джазової музики розрізняють наступні основні різновиди блюзового квадрату [1]:

Архаїчний блюзовий квадрат

$$
\begin{gathered}
\text { I7 |I7 |I7 |I7 | } \\
\text { IV7 |IV7 |I7 |I7 | } \\
\text { V7 |V7 |I7 |I7 (V7) || }
\end{gathered}
$$

Класичний блюзовий квадрат

$$
\begin{gathered}
\text { I7 |I7 (IV7) |I7 |I7| } \\
\text { IV7 |IV7 |I7 |I7 | } \\
\text { V7 |IV7 |I7 |I7 (V7) || }
\end{gathered}
$$

Блюзовий квадрат в джазовій музиці

$$
\begin{gathered}
\text { I6 |I6 (IV7) |I6 |I7| } \\
\text { IV7 |IV7 |I6 |VI7| } \\
\operatorname{IIm} 7 \text { |V7 |I6 | IIm7 V7 || }
\end{gathered}
$$

Насамперед, привертає увагу те, що, на відміну від класичного 8-ми тактового «періоду», блюзовий «період» має 12 тактів. Зважаючи на це, ми відмічаємо, що у блюзі не порушена чотирьохтактовість музичної структури. Але, як ми бачимо, у формуванні музичної структури блюзу на зміну двукратності виникае трьохкратність $(8: 4=2 ; 12: 4=3)$, що е цілком новітньою рисою для західно-європейської музики. Тому саме поєднання чотирьохтактовості, 3 одного боку, та трьохкратності, 3 другого боку, $є$ дійсно надзвичайною рисою музичної форми блюз. Можна зробити припущення, що така незвичайність у формуванні музичної структури, стала однією 3 причин, яка зумовила позитивне сприйняття музики напряму «блюз» західно-європейськими слухачами: звучання блюзу несе в собі, щось зовсім новітне для них, але, в той же час, не руйнуючи звичних слухових стереотипів. 
Зосереджуючи увагу саме на схемі класичного блюзового квадрату, та проаналізувавши іï, можна виявити дуже самобутні ознаки: в гармонічних зворотах блюзового квадрату присутня і автентичність і плагальність, причому в однаковій мірі. За кількістю функціональних акордових послідовностей, блюзовий квадрат в більшості складається з плагальних зворотів. Така плагальність визиває відчуття м'якості та згладженості у акустичному сприйнятті блюзової музики. Але в тих самих плагальних гармонічних оборотах закладена і домінантовість, яка, як відомо, с складовою автентичних гармонічних зворотів. Так би мовити «потенційна» домінантовість акустично присутня в блюзовому квадраті з тієї причини, що в акордовому складі блюзу присутні лише малі мажорні септакорди, а звучання малого мажорного септакорду у західноєвропейській музиці асоціюється зі звучанням домінант-септакорду. Через постійне використання малих мажорних септакордів в блюзові-му квадраті відбувається постійне зміщення очікуваного тонального центру, що створює відчуття безперервного розвитку та нескінченності. В порівнянні $з$ класичною традицією, де використання малого мажорного септакорду вимагає розв'язання та практично невід'ємно зв'язано 3 кадансом, функціональна напруга малого мажорного септакорду в блюзі так і не спадає у розв'язанні.

Така «нерозв’язаність» підтримус та доповнюс ладову невизначеність блюзу, тому що тільки після розв'язання домінантсептакорду можна почути який ладовий нахил - мажорний чи мінорний - має відповідний музичний матеріал.

Саме через наявність такої постійної гармонічної нестійкості та незаліксованості С. Коротков в своєї роботі «История современной музыки» відносить блюз за своїм походженням до східної музики. Його висновок спирається на те, що для західно-свропейської музики є харакгерними визначеність та конкретність, що відображається в темперованому строї (характерні інструменти рояль, гітара, духові інструменти), контрастних та чітких зіставленнях, в чіткій визначеності, як принцип викладення музичного матеріалу, на відміну від східних нетемперований інструментів (ситара, сантура), «переливання» звуку один в інший без чіткого зіставлення, «розмитої» консонансності та дисонансності. 3 походженням блюзу С. Коротков пов'язуе циклічність композиції блюзового квадрату: «Східна музика циклічна, як і світогляд Сходу, який вважає, що світ рухастьея по колу, від простого до складного і навпаки» [4, с. 23]. Саме ця циклічність побудови музичної форми і стала основою для музичної структури всіх стилів неакадемічної музики XX ст. В. Конен в своєму дослідженні «Третий пласт. Новые массовые жанры в музыке XX века» також відносить блюз до музики неєвропейського походження [3, с. 78]. 
Але, разом 3 ладовою невизначеністю та постійним нерозв'язанням напруги малого мажорного септакорду, в блюзовому квадраті можна відмітити і абсолютну логічність гармонічного розвитку. Якщо проаналізувати стратегічний гармонічний розвиток 12-ти такгового блюзового квадрату, то можна відмітити поступове накопичення гармонічної напруги: перша фраза починається 3 тонічної функщіі, друга - з субдомінантової, а третя - 3 домінантової [16, с. 57]. Таким чином між фразами відбувається цілком логічне, можна навіть сказати традиційне, зростання гармонічного напруження, не зважаючи на абсолютне порушення домінантового тяжіння між тактами. Але треба відмітити, що ця зростаюча гармонічна напруга через кожні 2 такти постійно спадає, 3 причини використання тонічної функції у 3-4, 7-8, 11-12 тактах. Іноді, в останньому такті квадрату замість тонічного може також використовуватися домінантовий септакорд. Це сдине місце $з$ усісї структури, де проявляється справжнє домінантове тяжіння V-I між 12 тактом попереднього та 1 тактом наступного квадрату. У такий спосіб зберігається структурна єдність музичної форми.

Однією 3 найцікавіших особливостей класичного блюзового квадрату $\epsilon$ його каденція: V-IV-I, яка побудована за абсолютно протилежними законами формування кадансу в класичній гармонії, і є свосрідною «візитною карткою» блюзу [8, с. 24]. Подібної каденції не наслідувала, навіть, джазова музика, для каденцій якої характерним є гармонічний зворот акордів II-V-I ступенів. Тому саме каденція V-IV-I, яку за ознаками (якщо спиратися на закони класичної гармонії) можна класифікувати, як перервану, с однісю з самобутніх та найвизначніших рис саме блюзової музики. Необхідно відмітити, що вищезгаданий гармонічний зворот $\mathrm{V}-\mathrm{I}$ між 12-м і 1-м тактом наступного квадрату використовується не завжди, що не дає можливості класифікувати його, як каденцію.

Якщо проаналізувати структуру 12-ти тактового блюзового квадрату, яка відображена у літерній схемі $\mathrm{AAB}$, то можна відмітити, що А - це перша фраза, друге А - це друга фраза, яка с повторенням першої фрази на дещо іншу гармонію, а В - третя фраза, яка є відшовіддю до перших двох. В такий спосіб в блюзі відображена запитально-відповідна структура, яка походить від його витоків - holer та work song. Така структура блюзу знайшла своє пряме відображення в джазовій музиці, для якої найхарактернішою формою с АABA (де смислове навантаження першої та другої фрази А і фрази В с ідентичними до блюзової структури, а четверта фраза А є своєрідною тематичною аркою чи репризою, що є цілком логічним для законів побудови музичної композиції). Вплив саме блюзового квадрату на формування найхарактерніших структур музичних композицій в рок-музиці простежус в своїй роботі Д. Ковач «Form in Rock Music: A Primer» [11, c. 66-69]. 
В музиці блюзу $є$ відображена тоніко-домінантова система, на якій побудована класична музика та яка була виявлена ще Ж. Ф. Рамо у першій половині XVIII ст. [6, с. 242]. Якщо розглянути натуральний звукоряд, то можна помітити, що 4, 5, 6 та 7 обертони створюють співзвуччя малого мажорного септакорду, що робить акустичне звучання гармонії блюзового квадрату близьким до людського слуху:

Але, як відмічас В. Конен, домінантовість проявлясться в блюзі зовсім інакше. Оскільки мелодика блюзу вийшла не 3 фіксовано темперованої європейської мелодики, то і гармонію блюзу треба сприймати інакше, а не в ракурсі європейської музичної культури [3, с. 79]. Хоча думки дослідників з цого питання різняться: одні вважають блюз проявом переважно африканської культури, другі переконані, що прояви африканської культури розчинилися в європейській музиці та стали частиною нової домінуючої культури [2, с. 14].

Треба відмітити, що логіка композиційного розвитку в блюзовому квадраті ідеально витримана: кульмінація гармонічного розвитку знаходиться на початку третьої фрази (9 такт), що цілком відповідас закону «золотого розтину». Як відомо, зміщення кульмінації ближче до кінця твору використовують для того, щоб надати музиці більшого драматизму, в той час, як зміщення кульмінації на більш ранній час призводить до більшої розрядженості та розслабленості. Розтапування ж кульмінації на початку третьої 3 трьох часток форми викликас відчуття пропорційності та стійкості.

За мелодичною структурою розрізняють 3 основні різновиди блюзового квадрату. Перший: коли друга фраза є повторенням першої (мелодично або в тексті, або і мелодично і в тексті), а третя відрізняеться від перших двох (вокальні композиції «Backwater Blues», «Everyday I Have the Blues», «Sent for You Yesterday»; інструментальні композиції «Billie's Bounce», «My Blues»). Другий: коли друга фраза повторює першу тільки в тактах 7-8, а в тактах 5-6 варіюсться, третя фраза, подібно до першого різновиду, є відмінною («Bessie’s Blues», «Straight, No Chaser»). Третій: так званий Riff blues, в якому один і той же матеріал повторюється три рази без змін на протязі 12-ти тактів («С Јam Blues», «One O'Clock Jump», «Sonnymoon») [12, c. 41-42].

Також, в процесі еволюції, блюзовий квадрат зазнав неабияких змін. Гармонія сучасного інструментального джазового блюзу була розроблена у часи ери bebop. Основний різновид сучасного інструментального блюзового квадрату можна позначити наступним чином:

$$
\begin{gathered}
\text { I7 |IV7 |I7 |Vm7 I7 | } \\
\text { IV7 |IV7 |I7 |IIIm7 IIIbm7 } \mid \\
\text { IIm7 |V7 |I7 VI7 |IIm7 V7 || }
\end{gathered}
$$


Як видно зі схеми, у сучасному трактуванні блюзова акордова прогресія розширялася традиційними джазовими акордовими зворотами II-V-I та напівтоновими акордовими зворотами. Але на цьому еволюція блюзової форми не скінчилася. В музикознавчій літературі згадують сімнадцять ї різновидів, які є основними [13, с. 36]. Необхідно зауважити, що перелічити всі існуючі блюзові прогресії неможливо, тому що імпровізаційний початок блюзової та джазової музики дозволяе безкінечно іiі трансформувати та винаходити нові її структури та різновиди.

Наведемо вислови з наукової музикознавчої літератури, які відмічають виняткове значення блюзу для неакадемічної музики ХХ ст.: «Процес формування блюзу завершився приблизно в 1910 році. Саме в такому вигляді основна блюзова форма (12-ти тактовий період) з характерною гармонійною схемою функціонує і в сучасному джазі» $[8$, с. 24]; «Джаз не мав більшого джерела ніж блюз. Блюз мас свої власні традиції, але також він с невід'ємною та більшою частиною джазової музики» [15, с. 237]; «Двома найбільш часто використовуваними в бібопі (та й, мабуть, у всьому джазі в цілому) типами гармонізації є блюз і «I Got Rhythm» [9, с. 89]; «Фанк - це стиль музики, в якому елементи джазу, поп, рок, госпел і Блюз злилися, щоб створити ритмічний, душевний саунд», «Фанк - це просто прискорений блюз» [18, с. 91, 33]; «Блюз - це провідник для бібопових скетових вокалістів Діззі Гіллеспі та Кенні Хагуда, і саме він був першим примірником звукозапису скетового співу» [17, с. 20]; «Музика hip-hop зростає з блюзу, джазу, фанку, року, ритм-ендблюзу і диско» $[14$, с. 19]; «... блюз є вкоріненою в традиції основою основ західного року. Як сказав Кіт Річардс, якщо ти не знаєш блюзу, немас сенсу братися за гітару і грати рок-н-рол або будь-яку іншу музику» [7, с. 63].

I справді, якщо перелічити музнчні компознції різноманітної стильової спрямованості, то можна з легкістю побачити, як глибоко насичена блюзом неакадемічна музика XX ст. Композиції в музичному стилі rock'n'roll: «Rock Around the Clock», «Hound Dog» (Elvis Presley), «Tutti Frutti» (Little Richard); в музичному стилі funk: «I Got You» (James Brown), «Watermelon Man» (Herbie Hancock); в музичному стилі soul: частина A у творі «Unchain My Heart» (Bobby Sharp, «What'd I Say» (Ray Charles); в музичному стилі pop: частина A у творі «Can’t Buy Me Love» (The Beatles), «Black or White» (Michael Jackson), «Down So Long» (Sting), приспів пісні «Mercy» (Duffy); в музичному стилі rock: «Tush« (ZZ Top), «Rock and Roll» (Led Zeppelin); в музичному стилі jazz. «St. Louis Blues» (William Christopher Handy), «Baby Elephant Walk» (Henry Mancini), «Now's the Time» (Charlie Parker) та багато ін.

Висновки. Враховуючи все вищезгадане, можна цілком впевнено сказати, що блюз, зокрема музична форма 12-ти тактового блюзу, дійсно є неординарним та основоположним явищем в неакадемічній музичній культурі 
XX ст. Логіку музичної форми 12-тактового блюзу, ступінь узагальнення досвіду передуючих їй музичних жанрів, іiі вплив на подальші музичні напрями та стилі можна порівняти навіть не тільки з 8-ми тактовим періодом у класичній музиці, а навіть 3 формою «сонатного алегро». До сьогодні в світовій музиці не з'явилося нічого подібного, що б мало такий же вплив на подальше формування музичної культури. Та, як казав один великих блюзменів Аарон Уокер: «Іенус тільки один блюз, а все, що відомо як тисячі й тисячі блюзів, що кочують по землі, це варіації одного єдиного блюзу в декількох тональностях, дещо інакше гармонізовані, але це завжди одне і те ж» [4, с. 13].

\section{Список використаних джерел}

1. Гурулев Л. Блюз: Гармония и форма [Електронний ресурс] / Л. Гурулев. - Режим доступу : http://www.7not.ru/jazz/6.phtml. - Назва з екрана.

2. Коллиер Д. Л. Становление джаза. Популярный исторический очерк. Пер. с англ. / Д. Коллиер. - Москва : Радуга, 1984. - 390 с.

3. Конен В. Д. Третий пласт. Новые массовые жанры в музыке XX века. / В. Конен. - Москва : Музыка, 1994. - 160 с.

4. Коротков С. А. История современной музики : курс лекций / С. Коротков. - Киев : Продюсерский центр LAV-studio, 1996. - 292 c.

5. Рогачёв А. Г. Системный курс гармонии джаза. Теория и практика / А. Рогачёв. - Москва : Владос, 2000. -128 с.

6. Холопов Ю. Н. Гармония. Теоретический курс / Ю. Холопов. - СанктПетербург : Лань, 2003. - 544 с.

7. Цалер И. Популярная музыка XX века: джаз, блюз, поп, рок, кантри, фолк, электроника, соул / И. Цалер. - Москва : Мир энциклопедий Аванта+, 2012. - $107 \mathrm{c}$.

8. Чугунов Ю. Эволюция гармонического языка джаза / Ю. Чугунов. Москва : Муравей, 1997. - $170 \mathrm{c}$.

9. Baker D. How to Play Bebop / D. Baker. - USA : Alfred Music, 1988. $151 \mathrm{p}$.

10. Christiansen C. Bebop Blues / C. Christiansen. - Fenton : Mel Bay Publications, 2000. $-80 \mathrm{p}$.

11. Covach J. Form in Rock Music: A Primer / J. Covach // Engaging music : essays in music analysis / J. Covach. - New York : Oxford University Press, 2005. P. 65-76.

12. Jaffe A. Jazz Harmony / A. Jaffe - Tübingen : Advance Music, 1996. $158 \mathrm{p}$.

13. Haerle D. Jazz /Rock Voicings for the Contemporary Keaboard Player / D. Haerle., - USA : Alfred Music, 1984. - 41 p. 
14. Hess M. Icons of Hip Hop: An Encyclopedia of the Movement, Music, and Culture / M. Hess. - California : Greenwood Press, 2007. - 688 p.

15. Levine M. Jazz Theory Book / M. Levine. - Petaluma : Sher Music Company, 1995. $-522 \mathrm{p}$.

16. Nettles B. Harmony 2 / B. Nettles. - California : Berklee College of Music, 1987. $-64 \mathrm{p}$.

17. Thomas O. Bebop: The Music and Its Players / O. Thomas. - New York: Oxford University Press, 1995. $-322 \mathrm{p}$.

18. Vincent R. Funk The Music The People and The Rhythm of The One / R. Vincent. - New York : St. Martin's Press, 1996. -228 p.

\section{References}

1. Baker, D. (1988). How to Ploy Bebop. USA: Alfred Music.

2. Christiansen, C. (2000). Bebop Blues. Fenton: Mel Bay Publications.

3. Chugunov, Yu. (1997). The Evolution of The Harmonic Language of Jazz. Moscow: Muravey.

4. Covach, J. (2005). Form in Rock Music: A Primer, Engaging music: essans in music analysis. New York: Oxford University Press.

5. Gurulev, L.(2016). Bhes: Harmony and form. Available at: $<$ http:/www. 7not.ru/jazz/6.phtml> [Accessed 07 May 2016].

6. Haerle, D. (1984). Jazz/Rock Voicings for the Contemporary Keaboard Plover. USA: Alfred Music.

7. Hess, M. (2007). Icons of Hip Hop: An Encyclopedia of the Movement, Music, and Culture. Califomia: Greenwood Press.

8. Jaffe, A. (1996), Jazz Harmony. Túbingen: Advance Music.

9. Kholopov, Yu. (2003). Harmony. Theoretical cotrse. St. Petersburg: Lan.

10. Kollier, D. (1984). The Establishment of Jazz. Popular Historical Scetch. Transl. from Eng. Moscow: Raduga.

11. Konen, V. (1994). The Third Layer. New Mass Genres in Music of the $20 t h$ Century. Moscow: Muzyka.

12. Korotkov, S. (1996). History of Contemporary Music. Kyiv: Prodiuserskyi Tsentr LAV-studio.

13. Levine, M. (1995). Jazz Theory Book. Petaluma: Sher Music Company.

14. Nettles, B. (1987). Harmony 2. California: Berklee College of Music.

15. Rogachev, A. (2000). A Systemic Course on Harmony of Jazz. Theory and Practice, Moscow: Vlados. 
16. Thomas, O. (1995). Bebop: The Music and Its Players. New York: Oxford University Press.

17. Tsaler, I. (2012). Popular Music of the 20th Century. Sazz, Bhes, Pop, Rock, County, Folk, Electronic, Soul. Moscow: Mir Entsiklopediy Avanta.

18. Vincent, R. (1996). Funk. The Music, The People, and The Rlythm of The One. New York: St. Martin's Press.

(๘) $1 y p 6$ 月. O., 2016 